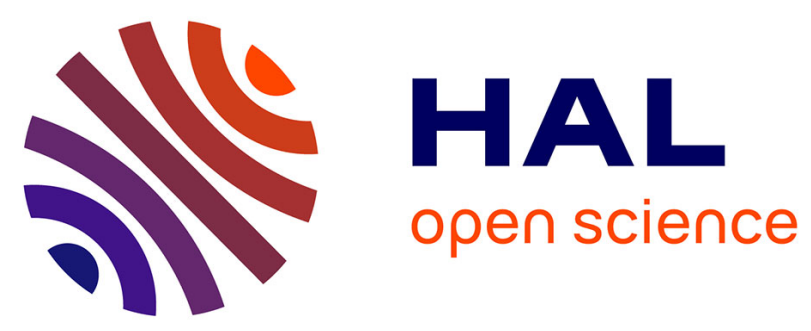

\title{
Coupled Experimental and Computational Approach for CABRI Power Transients Analysis
}

\author{
Olivier Clamens, Patrick Blaise, Jean-Pascal Hudelot, Johann Lecerf, \\ Bertrand Duc, Laurent Pantera, Bruno Biard
}

\section{- To cite this version:}

Olivier Clamens, Patrick Blaise, Jean-Pascal Hudelot, Johann Lecerf, Bertrand Duc, et al.. Coupled Experimental and Computational Approach for CABRI Power Transients Analysis. IEEE Transactions on Nuclear Science, 2018, 65 (9), pp.2434-2442. 10.1109/tns.2018.2847331 . hal-02429520

\section{HAL Id: hal-02429520 \\ https://hal.science/hal-02429520}

Submitted on 18 Mar 2020

HAL is a multi-disciplinary open access archive for the deposit and dissemination of scientific research documents, whether they are published or not. The documents may come from teaching and research institutions in France or abroad, or from public or private research centers.
L'archive ouverte pluridisciplinaire HAL, est destinée au dépôt et à la diffusion de documents scientifiques de niveau recherche, publiés ou non, émanant des établissements d'enseignement et de recherche français ou étrangers, des laboratoires publics ou privés. 


\title{
Coupled experimental and computational approach for CABRI power transients analysis
}

\author{
Olivier Clamens, Patrick Blaise, Jean-Pascal Hudelot, Johann Lecerf, Bertrand Duc, Laurent Pantera, \\ and Bruno Biard
}

\begin{abstract}
CABRI is an experimental pulse reactor, funded by the French Nuclear Safety and Radioprotection Institute (IRSN) and operated by CEA at the Cadarache research center. It is designed to study fuel behavior under RIA (Reactivity Initiated Accident) conditions. In order to produce the power transients, reactivity is injected by depressurization of a neutron absorber $\left({ }^{3} \mathrm{He}\right)$ situated in the so-called "transient rods" inside the reactor core. The CABRI reactivity injection system allows us to generate structured transients based on specific sequences of depressurization. For such transients, the time difference between the openings of two valves of the reactivity injection system has an important impact on the power pulse shape. A kinetic point code, SPARTE, was developed in order to replace the older DULCINEE code dedicated to the modeling and prediction of CABRI power transients. The SPARTE code includes new models of ${ }^{3} \mathrm{He}$ depressurization based on CFD calculations, variable Doppler coefficient based on Monte Carlo calculations and variable axial neutron flux profile. The density and Doppler models have a large impact on power transient prediction. For low initial pressure transients, the major uncertainty comes from the reactivity injected by the ${ }^{3} \mathrm{He}$ depressurization. For high initial pressure transients, the ${ }^{3} \mathrm{He}$ heating during the power pulse ("TOP effect") is responsible of an additional injection of reactivity that needs to be modeled precisely.
\end{abstract}

Index Terms-CABRI, Power transients, SPARTE, multiphysics

\section{INTRODUCTION}

C ABRI is an experimental pulse reactor funded by the French Nuclear Safety and Radioprotection Institute (IRSN) and operated by CEA (Commissariat à l'Énergie Atomique et aux Énergies Alternatives) at the Cadarache research center. Since 1978, the experimental programs have been aiming at studying the fuel behavior under Reactivity Initiated Accident (RIA) conditions. In order to study PWR high burn up fuel behavior under such transients, the facility was modified to accept a pressurized water loop in its central part, able to reproduce thermal-hydraulics characteristics representative of PWR nominal operating conditions (155 bar, $300^{\circ} \mathrm{C}$ ). This project, which began in 2003 and supported first commissioning tests from October 2015 to March 2017, was driven within a broader scope including both an overall facility refurbishment and a complete safety review. The global modifications have been conducted by the CEA project team and funded by IRSN, which is operating and managing the

O. Clamens, J. Lecerf, J-P. Hudelot, B. Duc, L. Pantera DEN CAD/DER/SRES CEA Cadarache, Bt 721. 13108 St Paul Lez Durance, France e-mail: olivier.clamens@cea.fr.

P. Blaise, DEN CAD/DER/SPEX CEA Cadarache, Bt 238. 13108 St Paul Lez Durance, France.

B. Biard, IRSN/PSN-RES/SEREX Cadarache, BP3 13115 Saint-Paul-LezDurance Cedex, France.
CIP experimental program (CABRI International Program), in the framework of an OECD/NEA agreement. The CIP program will investigate several UOx and MOX LWR spent fuel samples under RIA conditions, with a foreseen completion by the end of 2023. Power transients are generated by a dedicated so-called transient rods system [1] allowing the very fast depressurization of ${ }^{3} \mathrm{He}$ tubes positioned inside the CABRI core.

The first part of this paper is dedicated to the description of the CABRI power transients. In a second part, we will address the prediction of those transients and speak about the models that were added to the newly developed SPARTE code in order to improve the prediction precision. This paper also focuses on experimental and calculation uncertainties and their impact on the CABRI power transients.

\section{CABRI POWER TRANSIENTS}

\section{A. Transients measurement}

Two types of transients are needed for the CIP program. First ones are natural transients described in the following paragraph. Second ones are structured transients described in the next paragraph.

Specific boron-lined ionization chambers are used for measuring high power levels during steady states or during power transients [2]. In the case of power transients, several boron ionization chambers, located at increasing distances from the core (see Fig. 1), are used to cover the whole power range (i.e. from $100 \mathrm{~kW}$ to $\sim 20 \mathrm{GW}$ ). More details can be found in references [3]-[5].

\section{B. Natural transients}

Natural transients consist of single pulses with a FWHM (Full Width at Half Maximum) of approximately $10 \mathrm{~ms}$. They are made by single opening of the high flow rate channel (VABT01, see Fig. 2).

One example of natural transient is reproduced on Fig. 3. The reactivity injected by ${ }^{3} \mathrm{He}$ depressurization causes a power increase. The energy deposited in the fuel leads to a temperature increase. When the injected reactivity is balanced by Doppler and other reactivity feedbacks, the power decreases until a new equilibrium is reached. The reaction is then completely stopped by dropping the control rods. The parameters of the experiment are the control valve aperture (VABT03), the initial ${ }^{3} \mathrm{He}$ pressure, the rod drop instant, the initial stabilized power and the initial system temperature. The transient shape is mostly depending on the valve aperture and the initial pressure. The energy deposited in the core during 

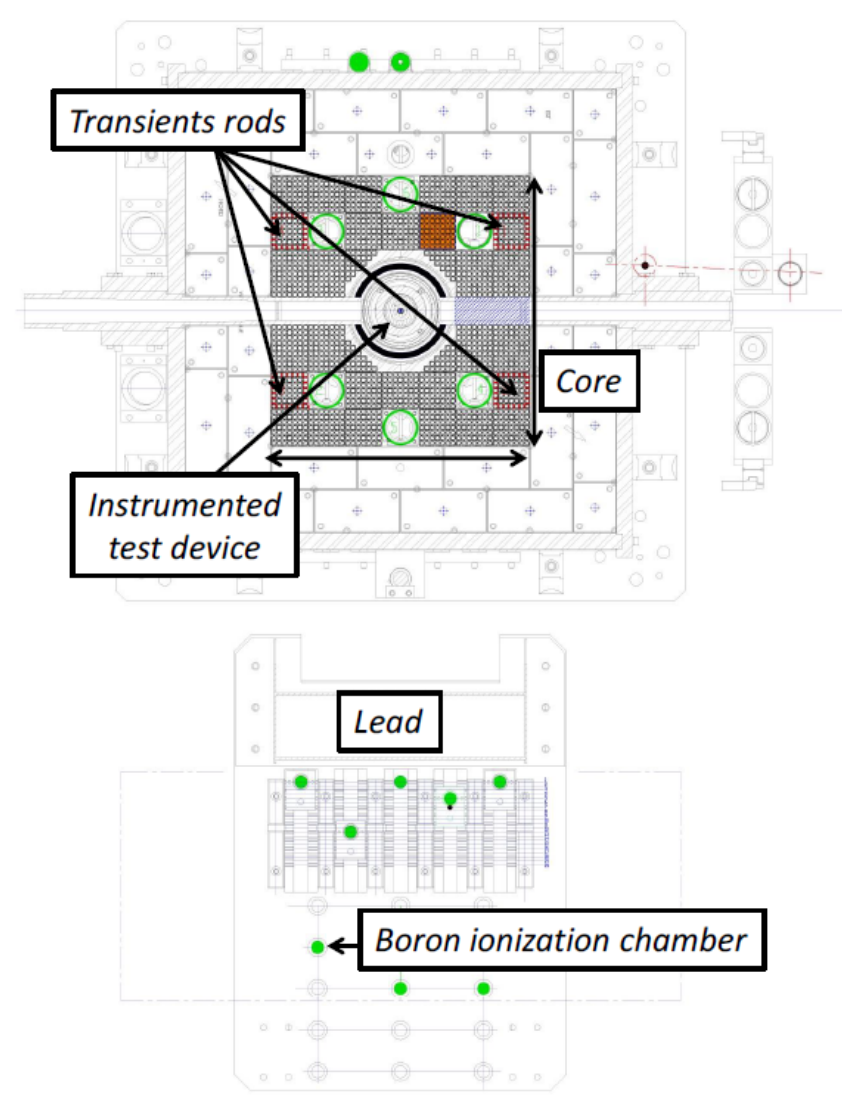

Fig. 1. Experimental boron ionization chambers near CABRI core

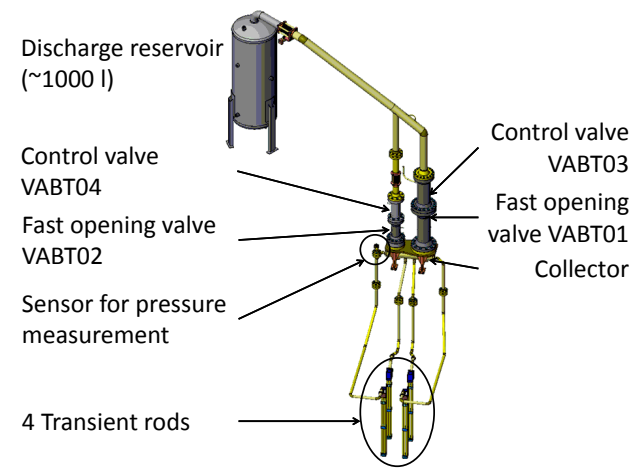

Fig. 2. Main components of the CABRI transient rods

the power transient is also controlled by the rod drop instant. The initial temperature is really important, in order to know the exact ${ }^{3} \mathrm{He}$ quantity in transient rods.

\section{Structured transient}

In order to be representative of other RIA conditions of NPPs (Nuclear Power Plants), it is necessary to be able to increase the FWHM of the transient. This can be done by opening successively the fast opening valves of the low and then of the high flow rate channels. When the net reactivity is close to $1 \$$, the high flow rate channel is opened to compensate during a short instant the reactivity feedbacks by a

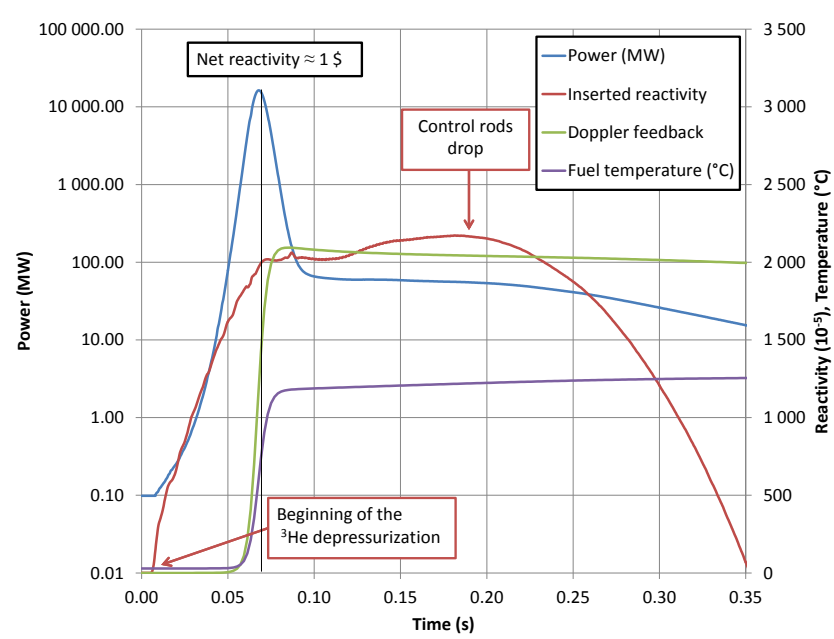

Fig. 3. Natural power transient and reactivity analysis

fast reactivity insertion. It allows thus a more important energy deposit during the pulse. The adjustment of the time difference between the openings of the fast opening valves allows us to generate so called "structured transients" characterized by FWHM varying from 20 to $80 \mathrm{~ms}$.

\section{IMPACT OF TIMING FOR STRUCTURED TRANSIENTS}

The experimentalists issue is to generate, with the CABRI core, the ideal power transient for the experimental purposes. One goal of the reactor commissioning tests performed in the first 2017 quarter was to generate power transients with a FWHM of $30 \mathrm{~ms}$ with a sufficient energy deposit. This can be achieved with structured transients as described in the last paragraph. In order to reach experimental goals, the transient parameters have to be precisely mastered. Considering an initial power of $100 \mathrm{~kW}$, the different parameters are:

- The apertures of the two control valves (VABT03 and VABT04),

- The ${ }^{3} \mathrm{He}$ initial pressure,

- The opening time of the two fast opening valves (VABT01 and VABT02).

\section{A. The timing issue}

The uncertainties on pressure and apertures are really small. However, an uncertainty exists on the time needed for the fast valves to open. A standard deviation of approximately $2 \mathrm{~ms}$ was observed on the opening time of VABT01. A major improvement was carried out during the CABRI renovation in order to reduce and master the uncertainty linked to the VABT02 opening. In the past, the second valve opening signal was triggered when pressure reached $90 \%$ of its initial value. The limitation of this method is that at the beginning of the depressurization, many oscillations are recorded. Those variations are linked to the different ${ }^{3} \mathrm{He}$ flows coming from different locations of the circuit. Those variations are reproducible from a depressurization to another and can also be observed in detailed CFD calculations. Few milliseconds of uncertainty were then added to the standard deviation observed 


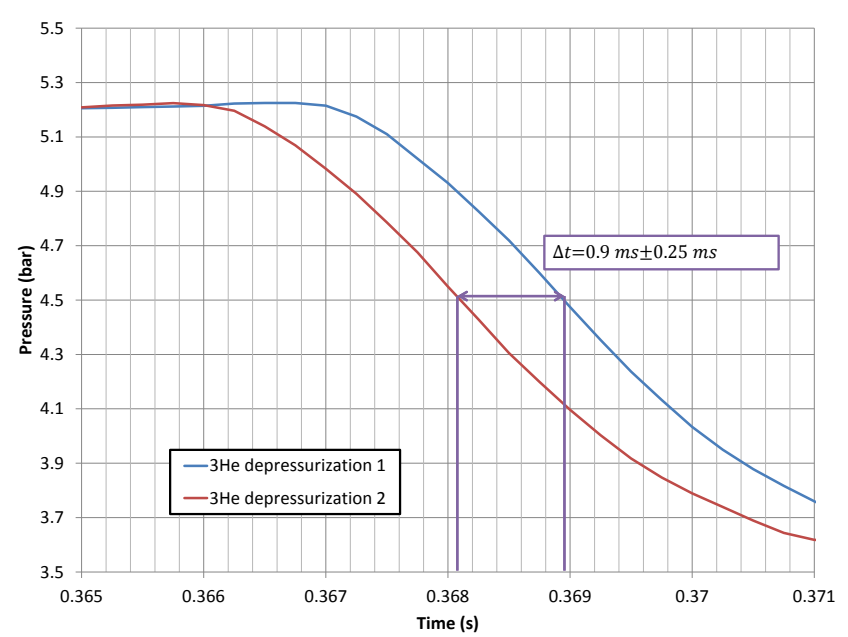

Fig. 4. Difference between 2 VABT01 opening times on 2 commissioning tests in the same conditions

for VABT01. The opening command of the second valve is now given by the specific control device when pressure reaches $75 \%$ of its initial value. In that zone, no variations are observed, only $0.25 \mathrm{~ms}$ of uncertainty can be added due to the acquisition rate. On Fig. 4, we can observe the time gap between the 2 openings of the high flow rate channels on two "structured" transients that have the same parameters. This gap is under $1 \mathrm{~ms}$, but still has a real impact on the transient shape.

\section{B. The impact on power transients}

The difference between the 2 power transients is depicted on Fig. 5. The two peaks climax at the same moment. However, the maximum powers ( $1 \mathrm{GW}$ gap) and FWHM (6 ms gap) are different. When the opening time comes faster, the power is going higher and the transient is a little thinner. Nevertheless, the energy deposited in the core is very close in the 2 cases. Before every irradiated fuel test, a campaign of approximately 10 transients without test rod in the central cell is performed. It results an uncertainty of approximately $5 \mathrm{~ms}$ on the FWHM for transients of $30 \mathrm{~ms}$ FWHM.

\section{SPARTE, A POINT KINETICS CODE DESIGNED FOR CABRI}

In order to analyze and to predict the CABRI power transients, a calculational approach is necessary. Currently, kinetics aspect is calculated by the DULCINEE [6] code and thermal-mechanics safety calculation are done by the SCANAIR [7] code. A new code is being developed in order to improve the prediction capacity as for kinetics aspects. The goal of this code is to improve the prediction of the CABRI power transients in terms of reached maximal power, FWHM, energy deposited and timing of the peaks.

SPARTE is a new code adapted to CABRI transients. It is based on the DULCINEE point kinetics code. Surrogate models and modifications of the datasets have been added in order to be more representative of the physical conditions. Surrogate

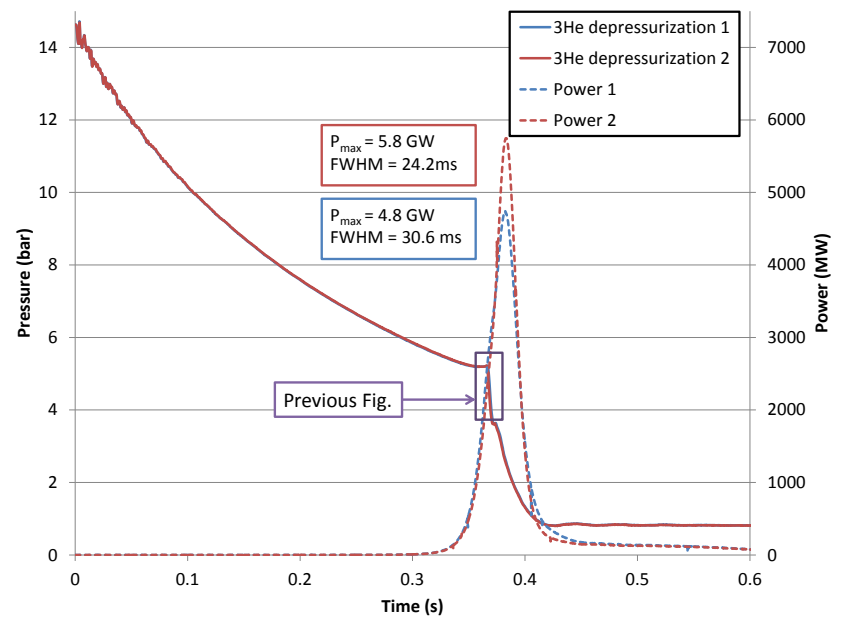

Fig. 5. Comparison of the two power transients resulting from the 2 similar depressurizations

models are based on Best-Estimate calculations (CFD [8] and Monte-Carlo [9]) and built with Artificial Neuronal Networks with URANIE [10]. In this part, we will present the four main improvements and their impact on the transient prediction:

- Surrogate model of the ${ }^{3} \mathrm{He}$ density in transient rods during depressurization,

- Variability of the Doppler coefficient as a function of the transient of power conditions,

- Axial neutron flux profile depending on the control rods position,

- Variability of the prompt neutron life time during power transients.

In every part, improvements will be added one by one on an example of transient. This example is a "natural" transient based on a depressurization beginning at 7 bar of ${ }^{3} \mathrm{He}$ with a full aperture of the high flow-rate channel.

\section{A. Surrogate model of helium density}

CFD calculations have been made in order to evaluate the Helium-3 density in the transient rods volume. A surrogate model estimating the ${ }^{3} \mathrm{He}$ density in the transient rods has thus been developed and implemented [8]. The ${ }^{3} \mathrm{He}$ density in the transient rods is more relevant than the ${ }^{3} \mathrm{He}$ pressure measured by the sensors (see Fig. 2) to take into account the impact of the ${ }^{3} \mathrm{He}$ temperature in the reactivity injection calculation. This model replaces the old model based on analytical solution of the ${ }^{3} \mathrm{He}$ depressurization (demonstration in [11]):

$$
P(t)=P_{0}\left(\frac{m(t)}{m_{0}}\right)^{\gamma}=P_{0}[B t+1]^{\frac{-2 \gamma}{\gamma-1}}
$$

Fig. 6 represents the difference between the density evolution and the pressure evolution. We can see that the pressure evolution is much faster than the density evolution. So, the reactivity injection calculated with the pressure curve is also much faster. That is why, the real power transient comes after the power transient calculated with the pressure model. The density model has a big effect on the transient shape and needs to be added to the code. 


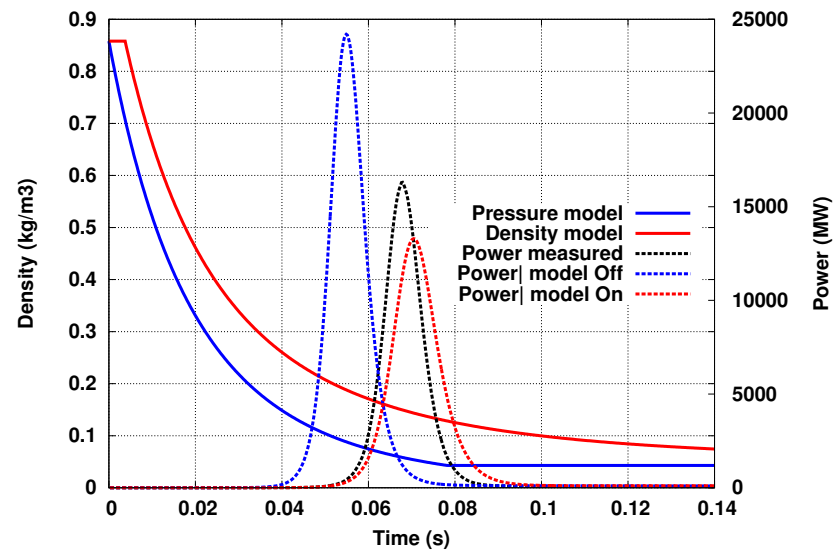

Fig. 6. Effect of density model on the power transient calculation

\section{B. Variability of the Doppler coefficient}

Neutronics calculations of the CABRI core using the French stochastic TRIPOLI4 [9] code show that the Doppler coefficient is varying with CABRI power transients conditions. The Doppler coefficient varies with fuel temperature and core poisoning due to Helium-3 and to control rods. This can be explained by the hardness of neutron spectrum. The ${ }^{3} \mathrm{He}$ neutron absorption is very effective in thermal condition. The more ${ }^{3} \mathrm{He}$ pressure in the transient rods important is, the harder the neutron spectrum is. The hardness of the neutron spectrum is also increasing with the elevation of the fuel temperature.

An Artificial Neuronal Network was created using the results of TRIPOLI4 simulations of the CABRI core. The parameters of the surrogate model are:

- The elevation " $\mathrm{z}$ " of the control rods (Hafnium),

- The density "d" of ${ }^{3} \mathrm{He}$ is the transient rods,

- The Fuel temperature "T" $\left(\mathrm{UO}_{2}\right)$

700 simulations were completed based on Latin hypercube sampling. The resulting surrogate model computes the multiplication factor depending on the different parameters. In SPARTE, the Doppler coefficient is on the integral form and is defined as follows:

$$
\rho_{D}=A_{D} *\left(\sqrt{T}-\sqrt{T_{0}}\right)
$$

We can also write the Doppler reactivity depending on the multiplication factor $\mathrm{k}$ as follows:

$$
\rho_{D}=\rho(T)=\rho(z, d, T)-\rho\left(z, d, T_{0}\right)
$$

Where:

$$
\rho=\frac{k-1}{k}
$$

From (2),(3) and (4) we can deduce (5):

$$
A_{D}=\frac{\frac{k(z, d, T)-1}{k(z, d, T)}-\frac{k\left(z, d, T_{0}\right)-1}{k\left(z, d, T_{0}\right)}}{\sqrt{T}-\sqrt{T_{0}}}
$$

Fig. 7 shows the evolution of the Doppler coefficient with temperature at different ${ }^{3} \mathrm{He}$ pressures in the transient rods, the control rod insertion being fixed. The Doppler coefficient increases in absolute value with fuel temperature and core

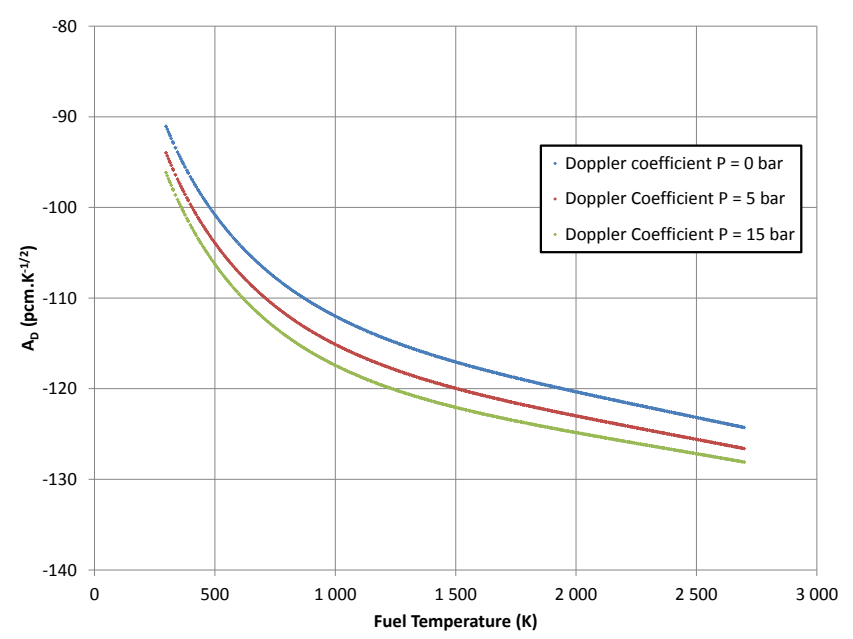

Fig. 7. Variability of the integral Doppler coefficient in CABRI core depending on fuel temperature and ${ }^{3} \mathrm{He}$ density

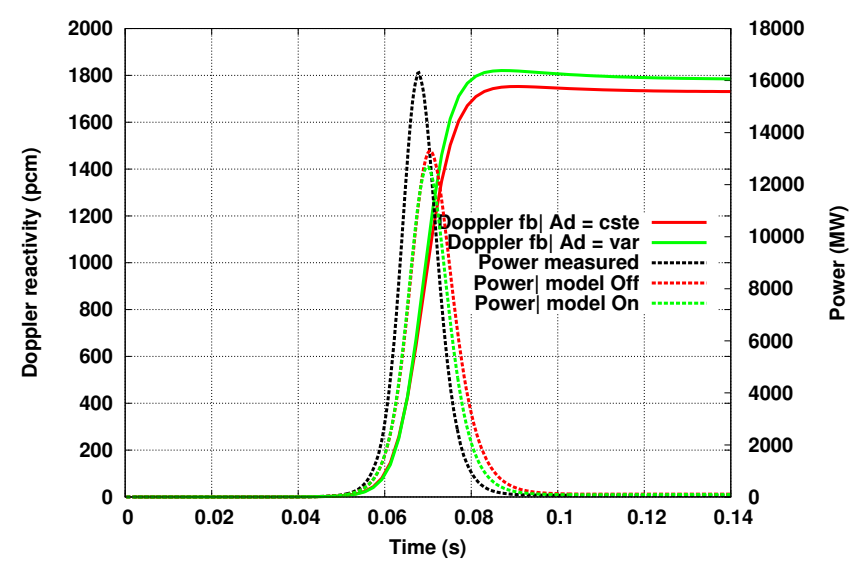

Fig. 8. Effect of Doppler model on the power transient calculation

poison quantity. So, during a transient, the Doppler coefficient decreases because of the ${ }^{3} \mathrm{He}$ depressurization, and in the same time increases because of the fuel temperature elevation. In the SPARTE code, the Doppler coefficient is then calculated as in (5), using the surrogate model of multiplication factor. The Doppler coefficient is calculated at each time step and for each fuel mesh.

On Fig. 8, is represented the influence of the Doppler coefficient model added to the SPARTE code. We can observe that the Doppler reactivity feedback is increasing higher with the model than for a constant value of the Doppler coefficient. It is due to an elevation of the absolute value of the coefficient with increasing temperature. The addition of the Doppler surrogate model in the simulation reduces the FWHM of the calculated power transients.

\section{Axial neutron flux distribution}

The axial neutron flux distribution is taken into account in the SPARTE code. It is used to calculate the energy deposition depending on the height of the fuel. It is also used to evaluate 


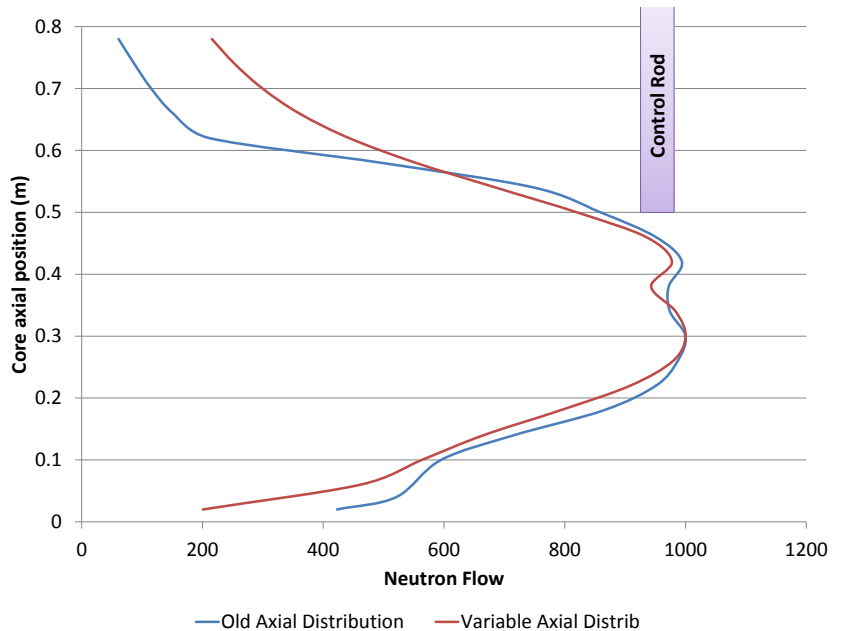

Fig. 9. Calculated axial distribution compared to the old axial distribution

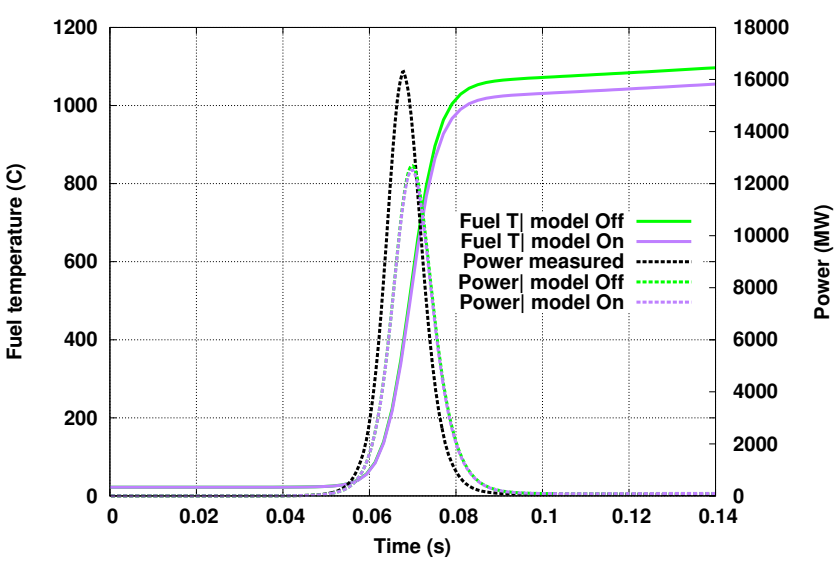

Fig. 10. Effect of axial distribution on the power transient calculation

the axial distribution of the reactivity feedbacks (Doppler, void, temperature). The CABRI case is specific because of the reactivity injection system. The control rods insertion, constant before triggering the depressurization and during the resulting pulse, until a manual scram order is initiated, depends at the first order on the initial ${ }^{3} \mathrm{He}$ density in the transient rods. Its dependency on the core cooling water temperature is secondary. That is why, the axial profile needs to be calculated for every calculation. Before the recent TRIPOLI4 calculation, the axial power profile in DULCINEE was coming from calculations of the hot channel near the control rods. The axial power distribution was therefore so low on the top of the core in the old axial profile (see Fig. 9). In the SPARTE code, a surrogate model based on the TRIPOLI4 calculations was added to calculate the core averaged axial power profile depending on the control rods insertion.

We can see that in this case, the new axial distribution has a moderate influence on the power transient shape. The axial neutron flux distribution is flatter, so that the temperature is better distributed. The Doppler reactivity feedback is then a little higher. This reduces slightly the maximum power (see

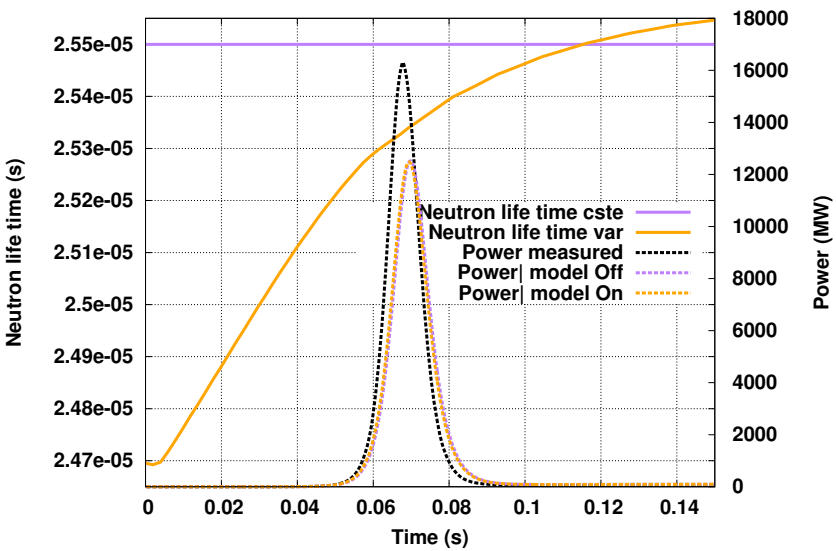

Fig. 11. Effect of neutron lifetime variability on the power transient calculation

Fig. 10).

\section{Variability of neutron lifetime}

The CABRI transients are characterized by a rapid withdrawal of the ${ }^{3} \mathrm{He}$ neutron absorbers, uniform within the core volume. We can easily assume that this withdrawal is responsible of an extension of the neutron life time. TRIPOLI4 is able to calculate kinetics parameters (effective neutron generation time " $\Lambda_{e f f}$ " and effective delayed neutron fraction " $\beta_{e f f}$ ) thanks to the Iterated Fission Probability method (IFP) [12]. The calculations demonstrate the variability of the neutron life time. The most influent parameter is the ${ }^{3} \mathrm{He}$ density. The second one is the control rods insertion.

The impact of the neutrons life time is presented on Fig. 11. We can observe that the neutrons lifetime is increasing with depressurization of the ${ }^{3} \mathrm{He}$. The neutrons lifetime being lower than reference at the beginning of the transient, the power peak arises shortly before the previous calculation. However, the neutrons life time staying close to the reference, and the impact on the transient calculation is low.

\section{E. TOP effect model based on experiments and CFD}

SPARTE's last improvement consists in modeling the TOP effect. This effect is detailed in [8]. The TOP effect comes from ${ }^{3} \mathrm{He}$ heating during power transients. As power increases, the thermal neutron flux also increases. So, the neutron absorption by ${ }^{3} \mathrm{He}$ intensifies. This reaction produces two charged particles : proton and tritium. One part of their energies is deposited in the ${ }^{3} \mathrm{He}$ gas by ionization before reaching the metallic wall of the transient rods. Denser is the gas, higher the probability of ionization is and more important the deposited energy is. The direct effect of this energy deposit is that the gas temperature increases. A temperature increase is equivalent to a pressure increase. The differential pressure between rods and flow channels implies a faster depressurization of helium from the transient rods. This finally implies a rise of the reactivity injection speed. A surrogate model computing a deviation of the depressurization rate during power increasing was added to the code. 


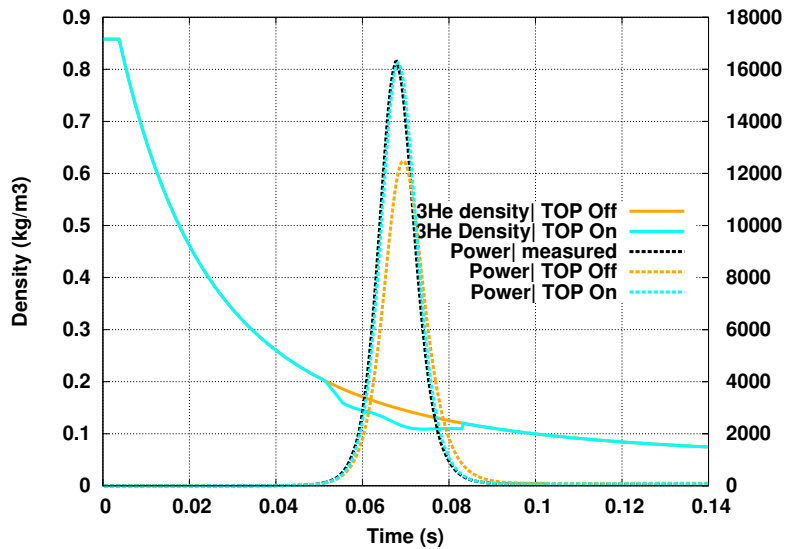

Fig. 12. Effect of the TOP effect model on the power transient calculation

The impact of the TOP effect is presented on Fig. 12. As we can see, the TOP effect model brings a deviation to the density evolution curve during the transient. The supplementary reactivity inserted through the TOP effect completes the prediction of the transient.

\section{F. Comparative tables}

In this paragraph, the successive elaborated models are tested on different power transients. Four criteria are compared to the experiment:

- The maximum power " $P_{\max }$ " of the transient,

- The Full Width at Half Maximum "FWHM" of the pulse,

- The energy "E" deposited in the core after $1.2 \mathrm{~s}$,

- The instant of the peak " $t_{\text {peak }}$ ".

All the transients compared are performed by single opening of a channel. Four tables show the four chosen examples :

- A transient with low initial pressure $(1.3$ bar $)$ and the maximum aperture of VABT03 (high flowrate channel) (Table I),

- A transient with a middle initial pressure (4 bar) and a low aperture of VABT04 (low flowrate channel) (Table II),

- A transient with a relatively high initial pressure (7 bar) and the maximum aperture of VABT03 (Table III),

- A transient with the maximal initial pressure $(\sim 14.5$ bar $)$ and a low aperture of VABT04 (Table IV).

For the four cases, the same approach is used. First, the measurement is presented. Then, a calculation shows the result of SPARTE with the 4 models presented dis-activated. The different models previously presented are then added one by one to the calculation. The last line of each table corresponds to the calculated power transient with all models activated.

We can observe that in all cases, the density evolution model and the Doppler coefficient model are the most influent on transient calculations. The density model brings the calculated peak closer to the measured peak in the time. The Doppler coefficient is higher than the reference in cases of high power (Table III), the calculated power being then lower. In all cases the Doppler model has for effect to reduce the FWHM. It is due to the elevation of the fuel temperature during the power
TABLE I

LOW INITIAL PRESSURE (1.3 BAR) TRANSIENT

\begin{tabular}{lllll} 
Models & $P_{\max }(\mathrm{MW})$ & FWHM $(\mathrm{ms})$ & $\mathrm{E}(\mathrm{MJ})$ & $\mathrm{t}_{\text {peak }}(\mathrm{ms})$ \\
\hline Measurement & 127 & 89.9 & 16.9 & 201 \\
Calc 0 & 469 & 48.2 & 35.2 & 141 \\
+ density & 297 & 63.9 & 28.9 & 191 \\
+ Doppler & 316 & 61.8 & 29.7 & 191 \\
+ Ax dist & 304 & 61.8 & 28.7 & 191 \\
$+\Lambda_{\text {eff }}$ & 302 & 62.3 & 28.6 & 191 \\
+ TOP & 302 & 62.3 & 28.6 & 191 \\
\hline
\end{tabular}

TABLE II

MIDDLE INITIAL PRESSURE (4 BAR) TRANSIENT

\begin{tabular}{lllll} 
Models & $P_{\max }(\mathrm{MW})$ & $\mathrm{FWHM}(\mathrm{ms})$ & $\mathrm{E}(\mathrm{MJ})$ & $\mathrm{t}_{\text {peak }}(\mathrm{ms})$ \\
\hline Measurement & 546 & 48.4 & 56 & 436 \\
Calc 0 & 743 & 44.8 & 99 & 366 \\
+ density & 472 & 57.4 & 66 & 434 \\
+ Doppler & 502 & 54.3 & 64 & 434 \\
+ Ax dist & 489 & 54.4 & 63 & 434 \\
$+\Lambda_{\text {eff }}$ & 486 & 54.3 & 63 & 433 \\
+ TOP & 522 & 50.3 & 63 & 431 \\
\hline
\end{tabular}

TABLE III

RELATIVELY HIGH INITIAL PRESSURE (7 BAR) TRANSIENT

\begin{tabular}{lllll} 
Models & $P_{\max }(\mathrm{MW})$ & FWHM $(\mathrm{ms})$ & $\mathrm{E}(\mathrm{MJ})$ & $\mathrm{t}_{\text {peak }}(\mathrm{ms})$ \\
\hline Measurement & 16300 & 9.59 & 192 & 67.9 \\
Calc 0 & 24200 & 9.21 & 278 & 54.8 \\
+ density & 13300 & 11.7 & 202 & 70.4 \\
+ Doppler & 12700 & 10.8 & 178 & 70.0 \\
+ Ax dist & 12500 & 10.8 & 176 & 69.7 \\
$+\Lambda_{\text {eff }}$ & 12500 & 10.8 & 175 & 69.5 \\
+ TOP & 16500 & 9.70 & 197 & 68.2 \\
\hline
\end{tabular}

TABLE IV

VERY HIGH INITIAL PRESSURE (14.5 BAR) TRANSIENT

\begin{tabular}{lllll} 
Models & $P_{\max }(\mathrm{MW})$ & FWHM $(\mathrm{ms})$ & $\mathrm{E}(\mathrm{MJ})$ & $\mathrm{t}_{\text {peak }}(\mathrm{ms})$ \\
\hline Measurement & 3300 & 24.0 & 105 & 375 \\
Calc 0 & 1200 & 35.2 & 107 & 324 \\
+ density & 842 & 42.3 & 68.3 & 369 \\
+ Doppler & 878 & 40.0 & 65.6 & 368 \\
+ Ax dist & 892 & 39.8 & 66.5 & 368 \\
$+\Lambda_{\text {eff }}$ & 886 & 39.4 & 66.5 & 366 \\
+ TOP & 3250 & 23.1 & 101 & 370 \\
\hline
\end{tabular}

increase, that influences the Doppler coefficient by elevating it. The Doppler reactivity feedback is then higher and the power reduces faster.

Table IV shows the importance of the TOP effect modeling. We can observe that the other models have for effect the respect of the transient timing. But some reactivity effect is missing and is then brought by the TOP effect.

We can also observe that for the low initial pressure transient (Table I), calculations are a bit far from reality. We will demonstrate in the next paragraph, that this gap can be explained by the uncertainty on pressure and on conversion 


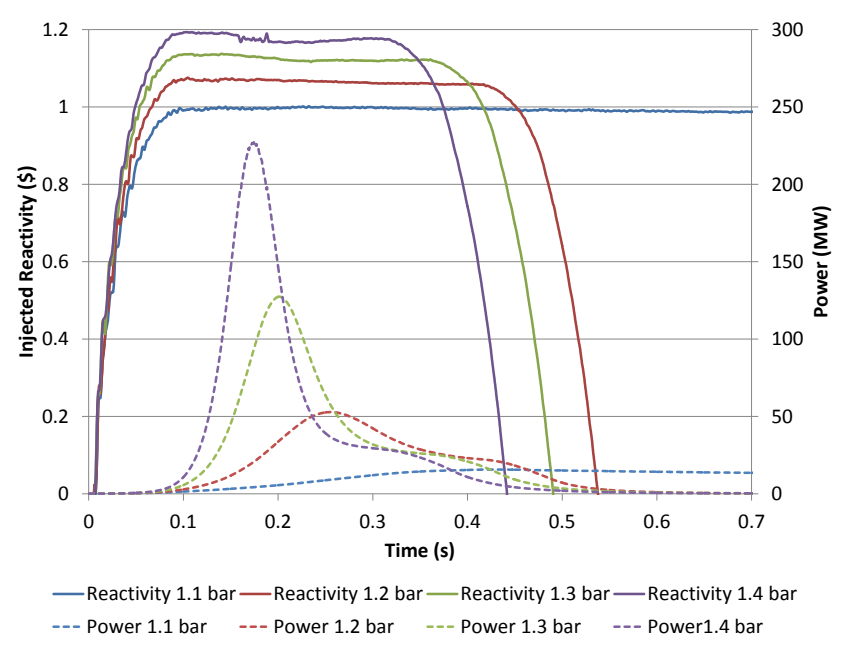

Fig. 13. Effect of small initial pressure variations on measured power transients

from pressure to reactivity.

\section{SEnsitivity STUDY NEAR 1 \$ OF INJECTED REACTIVITY}

In this section, we will try to explain the differential between calculation and experiment for low initial pressure transients, based on an uncertainty propagation approach. There is an uncertainty on the pressure measurement of approximately $0.2 \%$ and an uncertainty on ${ }^{3} \mathrm{He}$ reactivity vs. ${ }^{3} \mathrm{He}$ density. In cases of low pressure and an injected reactivity close to the effective delayed neutron fraction, the uncertainties are very influent on transient calculation.

\section{A. Experimental approach}

During the last commissioning tests, some transients have been carried out with an initial pressure close to 1.2 bar in order to observe the changing physics in this zone. We will compare four transients with close initial pressure $(1.1,1.2$, 1.3, 1.4 bar).

We can observe those transients on Fig 13. Below one dollar of injected reactivity, no power pulse is observed, the power increases slower but continues to increase before the rod drop. Above the dollar of injected reactivity, power is increasing until Doppler feedback compensates the injected reactivity.

\section{B. Computational approach}

The computational approach consists in propagating the input uncertainties on the power transient calculation. We assume uncertainties on initial pressure, final density, helium reactivity curve, Doppler coefficient model, depressurization model. Those uncertainties are assumed with a standard deviation of around $5 \% .20$ code runs are launched using a Sobol Design of experiments with normal distribution of the input parameters. The computational approach is tested on the 1.3 bar initial pressure case.

We can observe on Fig. 14 the influence of small uncertainties on the calculated transient of power. In this area of the

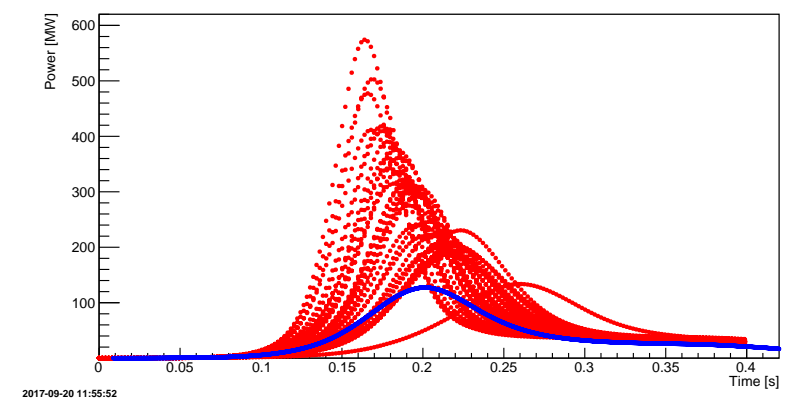

Fig. 14. Uncertainty propagation on the 1.3 bar case with the SPARTE code launched by URANIE

reactivity curve function of the ${ }^{3} \mathrm{He}$ pressure, we can assume that the reactivity model overestimates reality. The experimental power transient (blue) is located near the lower limit of the calculated transients. A good consistency is observed between experiment and calculation when uncertainties are taken into account.

\section{CONCLUSION}

The CABRI power transients generated by ${ }^{3} \mathrm{He}$ controlled depressurization are of two types: "natural" and "structured" and present very complex behavior depending on the kinetics and feedback coefficients. The current DULCINEE multiphysics code, while conservative, presents several assumptions that must be upgraded to enhance safety and operational margins of the CABRI tests. The first goal of the new SPARTE code is to predict at best the "natural" transients. The implementation of surrogate models for the ${ }^{3} \mathrm{He}$ density, more relevant than the pressure, for the Doppler coefficient, the axial neutron flux distribution and the neutron life time, based on Best-Estimates calculation and validated against measurements has greatly improved the calculation of those transients. For the prediction of the "structured" transients, we need first to calculate with a good consistency the transients issued from depressurizations of the low flowrate channel. When, the initial pressure is under $5 \mathrm{bar}$, SPARTE reproduces quite well the measured transients. Over this pressure, the "TOP" effect (described in [8]), affects the reactivity injection speed. We finally observed that the calculation of power transients with injected reactivity near $1 \$$ is very sensible to the different uncertainties. The analysis of the CABRI commissioning tests recently performed will improve the precision of the reactivity injected by the ${ }^{3} \mathrm{He}$ depressurization. 
APPENDIX A

NOMENCLATURE

\begin{tabular}{ll} 
Name & Definition \\
\hline$P$ & Pressure \\
$m$ & mass \\
$B$ & coefficient in $s^{-1}$ used in depressurization analytical law \\
$\gamma$ & Heat capacity ratio \\
$\rho$ & Reactivity \\
$\rho_{D}$ & Doppler reactivity \\
$A_{D}$ & Doppler integral coefficient \\
$T$ & Absolute temperature \\
$T_{0}$ & Initial absolute temperature \\
$k$ & Multiplication factor \\
$z$ & Height of insertion of control rods \\
$d$ & 3He density \\
\hline
\end{tabular}

[12] G. Truchet, P. Leconte, A. Santamarina, E. Brun, F. Damian, and A. Zoia, "Computing adjoint-weighted kinetics parameters in Tripoli-4 by the Iterated Fission Probability method," Annals of Nuclear Energy, vol. 85, pp. 17-26, Nov. 2015. [Online]. Available: http://www.sciencedirect.com/science/article/pii/S030645491500225X

\section{REFERENCES}

[1] B. Duc, B. Biard, P. Debias, L. Pantera, J.-P. Hudelot, and F. Rodiac, "Renovation, improvement and experimental validation of the Helium3 transient rods system for the reactivity injection in the CABRI reactor," in International Group On Research Reactors, 2014, Bariloche, Argentina, November 17 - 21.

[2] O. Clamens, J. Couybes, J. Lecerf, J.-P. Hudelot, B. Duc, L. Pantera, P. Blaise, and B. Biard, "Analysis of the CABRI power transients Prediction improvements using a combination of measurements and calculation." in Proc. Int. Conf. ANIMMA2017, Liege, Jun. 2017.

[3] J. Lecerf, Y. Garnier, J.-M. Girard, C. Domergue, L. Gaubert, and C. Manenc, "Study of the linearity of CABRI experimental chambers during RIA transients," in Proc. Int. Conf. ANIMMA2017, Liege, Jun. 2017.

[4] J.-P. Hudelot, E. Fontanay, C. Molin, A. Moreau, L. Pantera, J. Lecerf, Y. Garnier, and B. Duc, "CABRI facility: upgrade, refurbishment, recommissioning and experimental capacities," in Proc. Int. Conf. PHYSOR2016, Sun Valley, USA, 2016.

[5] J. P. Hudelot, J. Lecerf, Y. Garnier, G. Ritter, O. Gueton, A. C. Colombier, F. Rodiac, and C. Domergue, "A complete dosimetry experimental program in support of the core characterization and of the power calibration of the CABRI reactor," in Advancements in Nuclear Instrumentation Measurement Methods and their Applications (ANIMMA), 2015 4th International Conference on. IEEE, 2015, pp. 1-8. [Online]. Available: http://ieeexplore.ieee.org/abstract/document/ $7465504 /$

[6] G. Ritter, R. Berre, and L. Pantera, "DULCINEE. Beyond neutron kinetics, a powerful analysis software," in RRFM IGORR, 2012, prague, Czech Republic, March 18 - 22.

[7] V. Georgenthum, A. Moal, and O. Marchand, "SCANAIR a transient fuel performance code Part two: Assessment of modelling capabilities,' Nuclear Engineering and Design, vol. 280, pp. 172-180, Dec. 2014. [Online]. Available: http://www.sciencedirect.com/science/article/ pii/S0029549314002556

[8] O. Clamens, J. Lecerf, J.-P. Hudelot, B. Duc, T. Cadiou, P. Blaise, and B. Biard, "Assessment of the ${ }^{3} \mathrm{He}$ pressure inside the CABRI transient rods - Development of a surrogate model based on measurements and complementary CFD calculations," in Proc. Int. Conf. ANIMMA2017, Liege, Jun. 2017.

[9] E. Brun, E. Dumonteil, F. Hugot, N. Huot, C. Jouanne, Y. Lee, F. Malvagi, A. Mazzolo, O. Petit, J. Trama, and others, "Overview of TRIPOLI-4 version 7, Continuous-energy Monte Carlo Transport Code," 2011.

[10] F. Gaudier, "URANIE: The CEA/DEN Uncertainty and Sensitivity platform," Procedia - Social and Behavioral Sciences, vol. 2, no. 6, pp. 7660-7661, Jan. 2010. [Online]. Available: http://www.sciencedirect. com/science/article/pii/S1877042810013078

[11] O. Clamens, J. Lecerf, B. Duc, J.-P. Hudelot, T. Cadiou, and B. Biard, "Assesment of the CABRI transients power shape by using CFD and point kinetic codes." in Proc. Int. Conf. PHYSOR2016, Sun Valley, USA, 2016, pp. 1747-1758. 